\title{
MODEL FOR SUPPORT OF ORGANIZATION OF THE EXPEDITION WAREHOUSE OF A METALLURGICAL ENTERPRISE
}

\author{
Tomáš MALČIC \\ VSB - Technical University of Ostrava, Faculty of Materials and Technology, Ostrava, Czech Republic, EU, \\ tomas.malcic@vsb.cz
}

https://doi.org/10.37904/metal.2019.781

\begin{abstract}
The expedition warehouses are a key part of every distribution chain. Effective expedition warehouse management has a major impact on the overall quality of the finished products distribution process from manufacturer to customer. The metallurgical industry is characterized by a large stock of products stored, due to the production characteristics of the industry, such as large production campaigns, a wide products portfolio and a wide range of products quality grades. From the above, the importance of the efficient management of stock and the economical use of storage capacities is apparent. The aim of this article is to introduce the issue of the organization of the expedition warehouse of the selected metallurgical enterprise and to present the concept of the model for decision support in the storage of rolled products in the expedition warehouse. The main priority is the efficient use of storage capacities, personnel, handling equipment and optimization of warehouse operations, which will lead to reduction of the time required for order picking and loading.
\end{abstract}

Keywords: Metallurgy, warehouse management, products storage, expedition warehouse, decision support

\section{INTRODUCTION}

The aim of the study is to introduce the issue of the management of the expedition warehouse organization in a selected metallurgical company in the Czech Republic and to present the concept of the model for decision support in the expedition warehouse organization. The requirement for addressing of this issue originated from the previous research project focused on the logistics audit of expeditionary processes in a selected metallurgical enterprise in the Czech Republic (the specific university research of Ministry of Education, Youth and Sports of the Czech Republic no. SP 2017/63 and the ArcelorMittal Ostrava a.s. research project no. DS 9017715). During this logistics audit, a number of causes of downtime and wasting in logistics processes have been identified. One of the main causes of the identified shortcomings of logistics processes was the inefficient system of organizing the deposition of stored products [1]. The currently used system and methodology proved to be disadvantageous and inflexible. The inefficiency of the current system leads to an unsystematic layout of products in the expedition warehouse, which causes a large number of redundant warehouse operations and an increase in average loading times. Redundant warehouse operations are primarily manipulation with products, product tracing, and multiple loadings [2]. There is a number of studies dealing with the issue of product storage and warehouse layout. Studies vary from simple studies that optimize a specific warehouse to extensive studies dealing with complex storage management systems for general purpose or for a selected industry. In some cases, it was a simple reorganization of the warehouses according to the set criteria and in the other cases, it was a complex dynamic algorithm constantly processing all the criteria and offering the optimal solution [3,4]. In this case, it is a compromise of the approaches mentioned above because a specific warehouse was selected for solving, but the solution lies in proposing a complex dynamic algorithm for longterm use. This study is different mainly because it deals with the issue in the conditions of the metallurgical industry, which has been dealt with only by a few authors. 


\section{PROBLEM DEFINITION}

The process of designing the model for the support of the expedition warehouse organization, which will be presented below, was preceded by a process analysis of the current state of storage and expedition processes in the surveyed expedition warehouse of a selected metallurgical company in the Czech Republic. The process analysis was based on the analysis of historical data, measurement, and observation of process progress, questionnaires and structured interviews with production and expedition staff. This analysis focused mainly on the detail capturing of all logistical activities of product storage and expedition. Especially in terms of the sequence of these activities, their connections, associated data flow and measurable quantities such as duration, material quantity, and resources required. During the analysis, all the specifics and limitations resulting from the nature of the investigated process and the metallurgical industry, in general, was defined. Some of the main limitations are irregularity and unevenness in truck dispatch, insufficient storage and handling capacity, insufficiently integrated information systems, infrastructure unsuitable for truck transport, large dimension and weight of products, large production campaigns, a wide portfolio of manufactured products, a wide range of quality grades of manufactured products $[1,5,6]$.

The analysis of logistics processes in the expedition warehouse also included the analysis of stock, which was largely based on the inventory data about stored rolled products. Table 1 below shows a part of the inventory data. During the stock analysis, the following factors were paid attention: stored quantity, preferred storage locations, turnover rate, hourly performance, average loading time, average order size and customer behavior. The products were categorized by $A B C / X Y Z$ analysis for all observed factors. These categories serve as inputs in the decision-making process for selection of a storage location for stored bundles of rolled products in the expedition warehouse $[7,8]$.

Table 1 Evidence of stored products [own study]

\begin{tabular}{|c|c|c|c|c|c|c|c|c|c|c|}
\hline $\begin{array}{c}\text { Storage } \\
\text { place }\end{array}$ & $\begin{array}{c}\text { SAP } \\
\text { contract }\end{array}$ & Order & Melting & Quality & $\begin{array}{c}\text { Dimension } \\
{[\mathbf{m m}]}\end{array}$ & $\begin{array}{c}\text { Lenght } \\
{[\mathbf{m m}]}\end{array}$ & $\begin{array}{c}\text { Quality } \\
\text { control }\end{array}$ & $\begin{array}{c}\text { Weight } \\
{[\mathbf{k g}]}\end{array}$ & Volumes & Pieces \\
\hline A-A1 & $\begin{array}{c}31003892 \\
61-50\end{array}$ & 2113009 & $16812 \mathrm{~K}$ & $\mathrm{~K} 37 \mathrm{Z}$ & V40X40X5 & 12100 & Yes & 7110 & 3 & 201 \\
\hline $\mathrm{A}-\mathrm{A} 1$ & $\begin{array}{c}31003892 \\
61-250\end{array}$ & 2114009 & $17087 \mathrm{~K}$ & $\mathrm{~K} 37 \mathrm{Z}$ & V75X75X5 & 12100 & Yes & 2414 & 1 & 33 \\
\hline $\mathrm{A}-\mathrm{A} 1$ & $\begin{array}{c}31003892 \\
61-350\end{array}$ & 2114409 & $17144 \mathrm{~K}$ & $\mathrm{~K} 37 \mathrm{Z}$ & V90X90X8 & 12100 & Yes & 4676 & 2 & 38 \\
\hline $\mathrm{A}-\mathrm{A} 1$ & $\begin{array}{c}31003896 \\
63-130\end{array}$ & 2133009 & $17144 \mathrm{~K}$ & $\mathrm{~K} 37 \mathrm{Z}$ & V90X90X8 & 12100 & Yes & 2368 & 1 & 19 \\
\hline A-A1 & $\begin{array}{c}31003618 \\
64-10\end{array}$ & 4373208 & $10473 \mathrm{Y}$ & $\mathrm{C} 43 Z$ & $\mathrm{U} 50$ & 12100 & Yes & 3540 & 2 & 56 \\
\hline A-A1 & $\begin{array}{c}31003348 \\
62-70\end{array}$ & 5000608 & $93980 Y$ & C37Z & P30X4 & 6100 & Yes & 713 & 1 & 125 \\
\hline
\end{tabular}

\section{RESULTS}

In this section there are described results of analysis of the decision-making process in the expedition warehouse organization, identification of main factors entering the decision-making process and the main result of this work is presented, which is concept of the model for support of the expedition warehouse organization. In the process analysis, increased attention was paid to the process of selection of storage location for deposited bundles of products. This is because the layout of stored products has been identified as the most significant source of downtime and waste in storage and expedition processes. After the analysis of the current state of processes the phase of evaluation followed. In this phase bottlenecks, shortcomings, wasting, and downtime were identified. The causality, connections, and consequences of all identified phenomena were found. Furthermore, important factors have been separated from minor ones using quality management methods. Interrelationships and influence on the overall efficiency of storage and expedition processes were quantified for significant factors using mathematical equations to design a process model [10]. 
The main aim of the whole study was to acquire bases and design a concept of a model for support of the expedition warehouse organization in a selected metallurgical company in the Czech Republic. The model will primarily support organization of the expedition process in the decision-making in the selection process of storage location for the rolled products deposition. This part of the warehouse organization was selected because during previous projects and studies found out that the inefficient product storage system in the warehouse is the most significant cause of downtime and waste. All of this is a direct consequence of nonsystematic decision-making in the selection of storage location for individual products. It follows from the above that optimizing this part of warehouse management will bring the most significant improvement in storage and expedition processes. The process of designing a concept of the model of the system for a decision-support is based on information, data and knowledge gathered during the study and serves as a basis for creation of the final model.

\subsection{Analysis of the decision-making process in the organization of expedition warehouse}

The selection of storage location for rolled products deposition is an important part of expedition warehouse management processes. Because maximum utilization of storage capacity is necessary. Selection of the optimal storage location has a great impact on the streamlining of the entire expedition process. The key is to create a methodology for organizing a warehouse layout that ensures fluent and economical operation of the warehouse. The decision-making process of storing products in the surveyed warehouse is influenced by constructional, technological and safety factors. Furthermore, the selection of storage location depends on the type, size, weight, quality, quantity and turnover rate of the deposited products. The aim of the expedition warehouse management is to create an optimal methodology for products deposition that will ensure efficient use of storage capacity while minimizing material handling and costs related. Design of a new methodology for organizing warehouse layout is a very complex process that consists of a design of layout plan for storage locations and design of the decision-making process for products deposition. The whole methodology requires the prediction of quantity and type of production and expedition. It is a very complex prediction, especially for a large enterprise with a wide portfolio of manufactured products, such as a metallurgical enterprise. When designing the layout of storage locations, it is necessary to work with a number of alternatives and to choose a final option after a discussion between the expedition center management, production management, and logistics management $[7,9]$.

In the surveyed expedition warehouse, the expedition foreman and production foreman are responsible for the selection of storage locations for rolled products. Their task is to create and maintain a plan for layout and usage of storage locations. At the beginning of each production campaign, they together solve what type and quantity of products will be manufactured and what is the production plan for the near future. They also deal with the current state of the warehouse in terms of storage capacity utilization, products distribution between storage locations and available handling and personal capacities. They are also considering the nearest scheduled expeditions. They discuss all the above, considering the prescribed organizational plan and operating standards and norms and select the optimal storage locations and storage method for products manufactured. It is the duty of the production foreman to record storage location of individual bundles of products into the warehouse information system. Ideally, bundles of products are loaded directly onto the means of transport [1].

Although warehouse managers always try to select the optimal alternative, the decision-making process is largely based only on their experience and the currently used methodology is not clearly defined and standardized. The main reason why they cannot decide effectively about storage locations for specific bundles of products is the lack of the necessary information available at the time of decision.

Although the production foreman informs the expedition foreman about planned production campaign, this information often comes too late, because the receipt of orders is closed only three days before the start of the production campaign. Expedition workers thus do not have enough time to clear out suitable storage locations. 
On the contrary, the expedition foreman cannot effectively select appropriate storage locations for the planned production, because the foreman doesn't have enough information about the planned expeditions. This is due to the lack of integration of enterprise information systems. It has been found out that information about planned expeditions are often known in relatively long advance, but are not available to the expedition warehouse staff. If the foreman doesn't have information about the date of the expedition of a given production, then the foreman doesn't have the possibility to organize the deposition of products in response to the expedition.

Due to mentioned shortcomings, there is an inefficient distribution of production between storage locations, which causes redundant warehouse operation such as material manipulation and truck movement. The problem with the process of product deposition and with the warehouse operations, in general, is also insufficient staffing of expedition crews at the peaks of production of rolled products with high hourly performance, when there is a conflict of priorities between the deposition of manufactured products and the loading of products for the expedition.

\subsection{Identification of main factors entering the decision-making process}

In this part of study, the focus was on the factors influencing the decision-making process in the selection of storage location for products deposition. Factors entering the decision-making process chosen as main are general preferences (production, logistics, safety), loading (means of transport, loading specifics), order type (type extern/intern, size), customer, product (type, quality, quantity, length), planned expeditions, warehouse situation, special adjustments, day and time of deposition, deposition method and statistical data $[6,10]$.

For all the factors listed above, partial analyzes are currently underway to determine their priorities in terms of impact on the optimization of expedition processes. Data are collected and analyzed to reveal trends and patterns in the development of the values of all involved variables. Outputs of these data will serve for the design of the model for prediction of development of all factors. Based on the historical and predicted data, the priorities of individual factors for their consideration in decision-making will be determined. Prioritization of factors considerations will also be discussed with the managers of the production department, managers of the expedition warehouse and managers of the entire enterprise to develop a methodology for organizing the expedition warehouse layout, which will meet strategic, tactical and operational requirements. Outputs of the all partial analyzes will be combined using multi-criteria decision-making methods such as the analytical hierarchical process AHP [7,9].

\subsection{Concept of the model for support of the organization of expedition warehouse}

As mentioned in the previous chapters of the article, the model will respect all restrictions, specifics, and requirements of the surveyed warehouse. It will work with preset priorities, warehouse status, seasonal effects, scheduled expeditions, production characteristics, customer requirements and it will also take management's strategic plans into account. The model will dynamically evaluate all relevant input data. Data will enter the model in the form of preset export reports from the appropriate enterprise information systems. It will continually compare current data about all considered parameters and will recommend a storage location for the product optimally suited to all factors in relation to the preset parameters and priorities. This in practice means that the model of the system will be set to avoid sub-optimization for one of the factors at the expense of another. For this reason, the minimum and maximum values that can be achieved will have to be set for each considered factor. This will avoid situations where, for example, the model would recommend storage of products that would be perfectly suited for operating the production section and deposition of bundles of products. However, it would then be completely unsatisfactory for the needs of the expedition, where there would occur a large number of redundant material manipulations, handling equipment movements, personnel movements, and means of transport movements. And it would happen that saving of resources and time gained from products deposition, would be far from covering the wasting of these resources in the subsequent expedition of deposited products. 


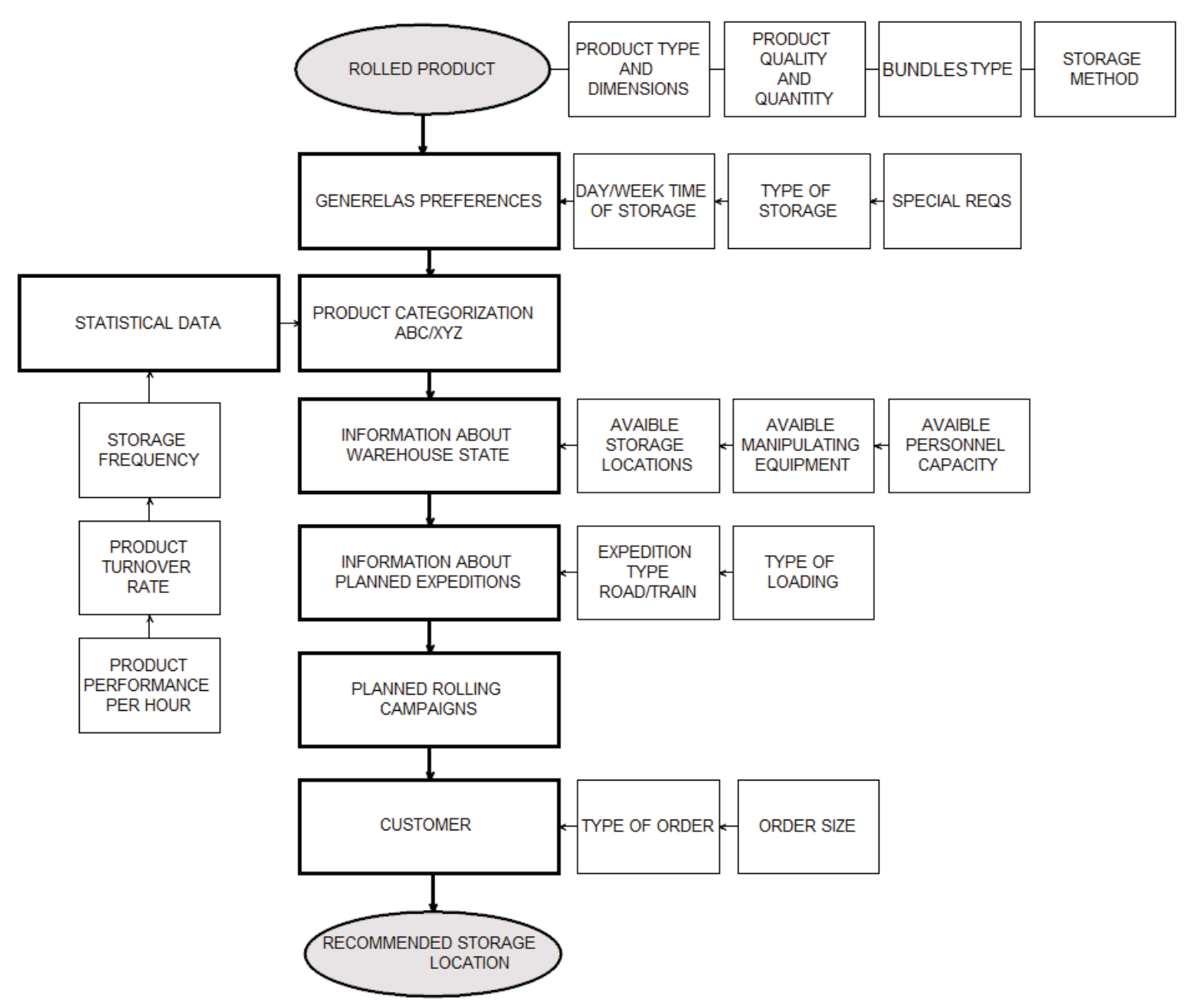

Figure 1 Concept of model for support of organization of expedition warehouse [own study]

Figure 1 is a flowchart depicting a schematic draft of a concept of the model for support of the expedition warehouse organization. The final form of the model will certainly change during its development, especially the order of a consideration of the factors. The final order and the priorities for consideration will be determined by the management of the expedition warehouse, production, and logistics. The schematic diagram serves only for an understanding and an introduction of a function of the proposed concept. The scheme is very simplified compared to the expected final form of the model. The goal is to program a complex algorithm, which will consider all mentioned factors at once and in real time. The flowchart in Figure 1 shows the current idea of the possible course of the evaluation algorithm, which is based on previously known facts and identified phenomena. The input impulse into the decision-making process should be information about manufactured rolled products for which the storage locations need to be selected. This information will consist of data about the type, dimensions, quantity, and quality of the products. Furthermore, data about the type of bundles of products and about storage method. Then the general preferences will be considered for a given type of production, time of production, type of storage and for special requirements such as additional treatment (coating, binding, grinding). The product will be categorized based on historical statistical data about storage frequency, turnover rate, and hourly performance. Subsequently, the current warehouse situation will be considered in terms of available storage locations, handling equipment and personnel. Another considered factor will be the planned expeditions and the type of transport used for these expeditions along with the type of loading. Next the planned production campaigns will be considered in terms of product type and quantity. In the end, the target customer for a given product will be also considered. Above all, the size of his order and 
the history of his behavior in terms of a material withdrawal will be important. Once all the factors influencing the decision-making process are processed and evaluated. The algorithm will select a storage location or a set of locations, which meet the required values for all factors.

\section{CONCLUSION}

An inefficient and non-systematic approach to the selection of storage location for the rolled products deposition in the expedition warehouse was identified as a major cause of downtime and waste in logistics processes. The outputs of the previous process analysis served as a basis for the design of the model. The main outputs used for design purposes were the specifics and limitations of the metallurgical industry and the surveyed warehouse, and factors influencing the decision-making process and the description of this process. The proposed concept can be described as a dynamic multi-criteria model of the decision-support system for the rolled products deposition in an expedition warehouse in a selected metallurgical company in the Czech Republic. The output of the model will always be the recommendation of the optimal storage location for the currently manufactured type of product. Alternatively, multiple storage options may be recommended based on the optimum values of the various factors and the expedition foreman will consider, which factor has priority in the given situation. The contribution of this article is mainly the schematic concept of the design of the model. The proposed model will serve as a support tool for managers to manage the organization of the warehouse layout. The model will enable workers to make better choices based on a large amount of relevant and timely information. The application of this support model in practice will optimize the utilization of storage capacities, reduce wasting of resources and time and will streamline expedition processes.

\section{ACKNOWLEDGEMENTS}

This research was supported by the specific university research of Ministry of Education, Youth and Sports of the Czech Republic no. SP2019/62.

\section{REFERENCES}

[1] MALČIC, T., LENORT, R., BESTA, P., ČECH, M., WICHER, P. Optimization of Logistics Costs In Dispatch Processes Of Metallurgical Enterprises. Hutnické listy. 2018, vol. 71, no. 2.

[2] BOLTEN, E.F. Managing Time and Space in the Modern Warehouse: With Ready-to-use Forms, Checklist \& Documentation. New York: AMACOM, 1997.

[3] MANZINI, R. et al. Design of a Class Based Storage Picker to Product Order Picking System. International Journal of Advanced Manufacturing Technology, 2007, vol. 32, no. 811.

[4] ZHOU, L. et al. Study on a Storage Location Strategy Based on Clustering and Association Algorithms. Soft Computing, 2018.

[5] BREWER, A., BUTTON, M., HENSHER, K. J, DAVID, A. Handbook of Logistics and Supply Chain Management, vol. 2. Emerald, Inc, 2008.

[6] SAMOLEJOVA, A., LENORT, R., LAMPA, M., SIKOROVA, A. Specifics of Metallurgical Industry for Implementation of Lean Principles. Metalurgija. 2012. vol. 52, no. 3, pp 373.376.

[7] RICHARDS, G. Warehouse Management: a Complete Guide to Improving Efficiency and Minimizing Costs in the Modern Warehouse. Third edition. London: Kogan Page, 2018.

[8] RUSHTON, A., CROUCHER, P. a BAKER, P. The Handbook of Logistics and Distribution Management. 5th ed. London: Chartered Institute of Logistics and Transport, 2014.

[9] LENORT, R. Production Logistics Concepts and Systems: Potential for Use in Metallurgical and Waste Processing Companies. Krakow: AGH University of Science and Technology Press, 2010.

[10] SÁ, J.C., DINIS-CARVALHO, J., RUI, M.S. Waste identification diagrams. In CLME 2011: 6th Conference LusoMoçambicano de Engenharia. Maputo, Mozambique, 2011. 